\title{
Analysis and monitoring of electrical grounding grid encapsulated with concrete: case study using simulation in finite element method
}

\author{
Thiago Martins Pereira, Rodrigo Alves Lima, Viviane Margarida Gomes, Wesley Pacheco Calixto, \\ Aylton José Alves
}

\begin{abstract}
This work study the influence of concrete, plaster, clay and others buried structures in grounding systems. Comparison of soil characteristics between dry and rainy seasons on different grounding systems. The study includes comparison of six different grounding system on dry season and wet season. Simulations in finite element method was performed for tree layer stratified soil and the electrostatic equipotential surfaces were mapped into the region of interest.
\end{abstract}

Index Terms - Grounding Systems, finite elements method.

\section{INTRODUCTION}

$\mathrm{H}$ ERBERT G. Ufer was in charge of the facilities from Davis Montana military base, one of the tasks was to protect the bombs warehouse from atmospheric discharge [1] He utilized structural system to reinforce the grounding efficiency from the traditional grounding rod system [2]. Subsequent inspections of the installations showed that combined grounding systems presented lower resistance and greater consistency in high electrical resistance soils than grounding systems without concrete structures[3]. Concrete is a hygroscopic substance and therefore, absorbs water more easily than lost. For that reason, concrete presence in soil helps to keep soil humidity levels and grants a lower resistance to soil [1].

Grounding systems are used for many different functions, from noise reduction for better functioning of electronic equipment to security applications, power systems and substations grounding is important to maintain stable and secure systems for equipment and users [4].

This work starts from the hypothesis that the electrical behavior of soil is altered by climate seasonality [5]. The grounding grid efficiency was studied during the rainy season and during dry season in combined and non-combined systems.

Concrete used in construction basically consists of a mixture of cement, water and crushed stone. Buried concrete block has equivalent behavior to a semiconductor element with resistivity between $30 \Omega$ and $90 \Omega$ as IEEE indicates their standardizations [3] [6].

Grounding probes were build using different types of material.in monitoring the current on dry soil and moist soil studying behavior of materials on different humidity.

Concrete hygroscopic feature helps both concrete and soil to remain moist, lowering soil resistance [2]. This moisture is present between the solid particles of the soil, so it consists basically water, organic minerals and dissolved inorganic [7]. Utilization of the structural columns was also mentioned to reinforce the grid in its function [8].

In the 70's it was indicated the use the enclosed electrodes in concrete, with a view to improve grounding grid performance. The lack of standardization in telecommunications wiring was a concern among operators and only in 1991 there was standardization and regulation, facilitating the use of ground [11].

Among the main functions of grounding Because the grounding system importance, are highlighted four most common applications. Protection systems and security function to living beings and protection to equipment [11]. Thus, grounding installation purposes includes personal safety in the handling and maintenance of equipment, avoiding dangerous tensions. Grounding systems are also capable of providing overvoltage protection, limiting noise and crosstalk in transmission systems and serve as return path for DC circuits. Additionally, they serve as protection in case of lightning [12].

Grounding probes were built using different types of composition from clay to concrete with salt. The different hygroscopy from materials makes different electric current drained. 


\section{Methodology}

\section{A. Data Acquisition}

To verify the influence of concrete efficiency of grounding systems built two-ground grid. These structures were installed on same topographical area and have same number of rods, differentiated only by the presence of one of concrete in mesh. Data acquisition made at two-week intervals to monitor the effect of climate seasonality in meshes checking the humidity, temperature and grounding resistance.

The Wenner method is a method for measuring resistivity of homogeneous soil which four rods are inserted into equally spaced ground like Figure 1.

The central terminals are used to determine the voltage side terminals are for power insertion into the ground.

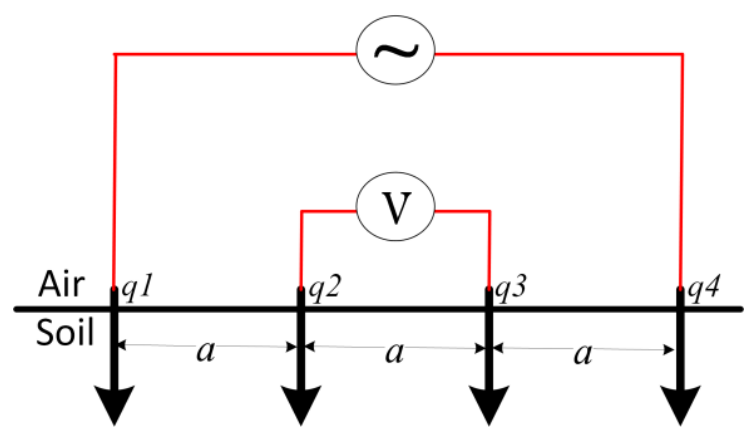

Fig. 1. Simplified disposition in soil of six different grounding grids

Current flowing between the rods produce a potential in voltage measuring rods, with voltage and current values, Wenner show a correlation between soil resistivity and measured resistance. Increasingly the rods distance, more current will penetrate into soil and a deeper soil resistivity will be measured.

Another six grounds grid were built and installed on another place on same topographical area. This six was inserted on soil

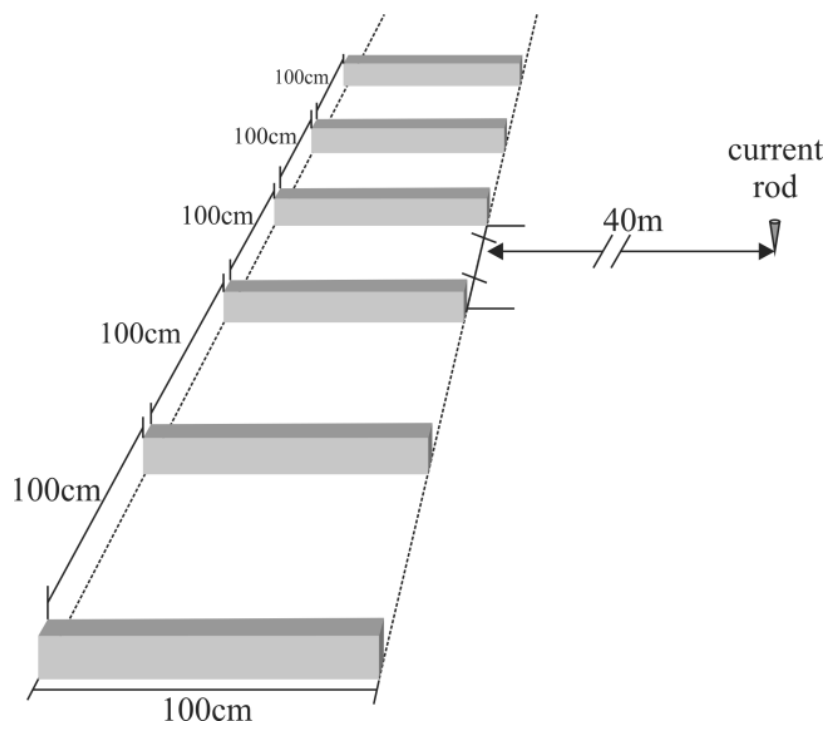

Fig. 2. Simplified disposition in soil of six different grounding grids has different constitution using the same $50 \mathrm{~mm}$ conductor. The difference on constitution display how de grounding

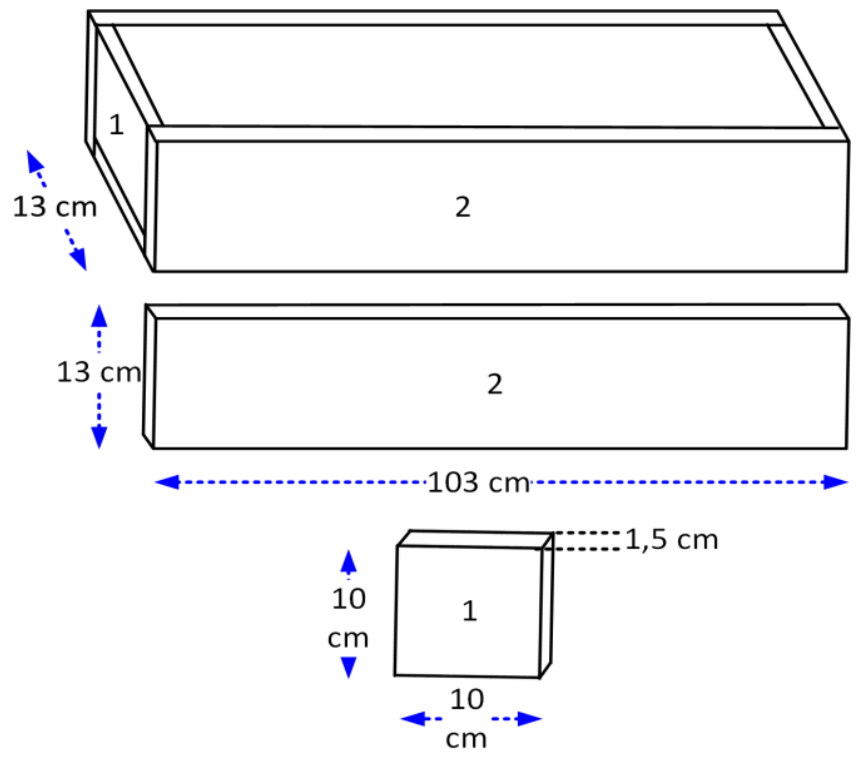

Fig.3. Grounding system mold

resistance changes in different soil. The Figure 2 displays how was disposed and measured the grounding resistance.

The first on left has concrete, gravel and salt, second concrete and gravel, third only concrete, fourth plaster, fifth clay and last on right has only conductor buried on soil.

The mold used to build grounding system guarantees size of grounding systems. Grounding systems has $100 \mathrm{~cm}$ length, $10 \mathrm{~cm}$ depth and $10 \mathrm{~cm}$ of width. The mold used is described on Figure 3.

The fall-of-potential method was used to obtain curve that represents the locations of grounding resistance. [17] This method consists the equipment called megohmmeter that generates a know current, between earth electrode and the outer stake, while the drop voltage potential is measured between the earth stake and the outer current stake. [18] The distance used between earth stake and current stake was $40 \mathrm{~m}$ like NBR 15749 says. The potential stake is moved every 5 meters from earth stake to current stake. There is seven different values measured on these grounding systems. According the measured values, is drawn a graphic that shows grounding resistance. The expected graphic on Figure 4 shows resistance with distance and the influence of earth stake and current stake on measure. The linearity region distance between earth stake and current stake changes according different soil types. Regularly the linearity region is $37,5 \%$ to $62,5 \%$ between the roads. In case of the curve don't present the linearity level some mistake may have occurred on rods or cable connections.

\section{B. Simulation Software}

Finite element method (FEM) allows to simulate and validate data obtained from soil stratifications [13]. Performance of ground and influence of neighboring structures to ground grid 


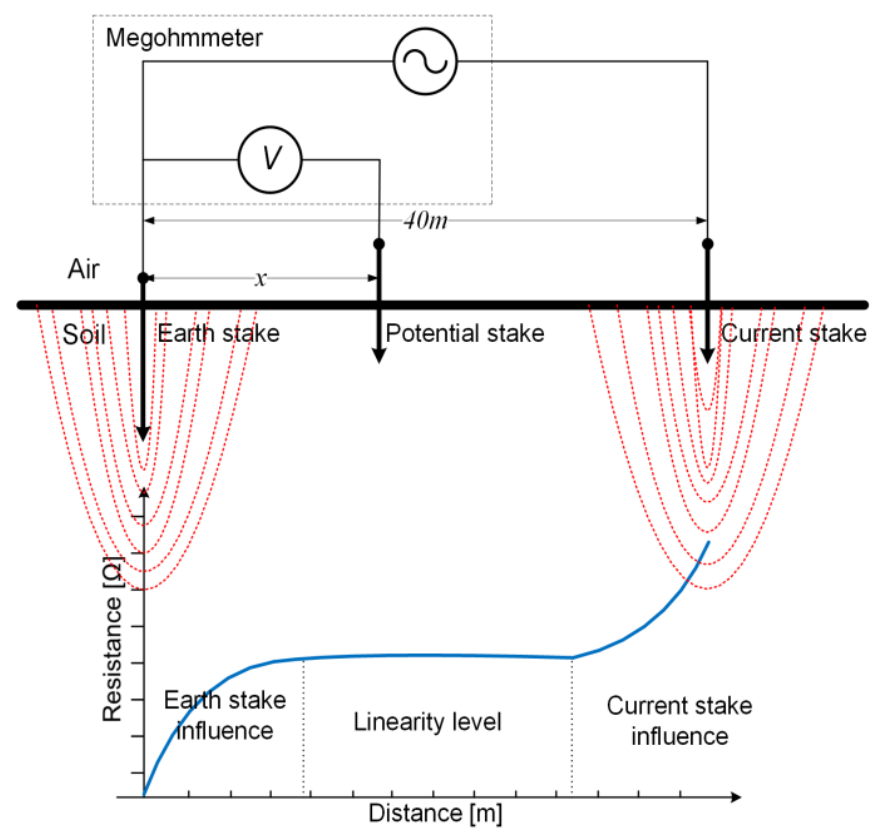

Fig. 4. The fall of potential method

are observed for solution of potential surfaces in plane and on edge of layers. Simulation allows observing dissipation of electric current and influence of aggregate structures to ground grid [14].

Finite element method consists of a mathematical analysis based on discretization of a continuous environment into small elements while maintaining the same characteristics of the original environment. All elements are described in differential equations and then they are solved using mathematical models. The accuracy and performance of method depends on number of elements and nodes. Smaller elements and consequently greater amount thereof and greater number of nodes in mesh greater will be precision of resolution of problem. Even when dealing with an approximation method, increasing amount of elements size tends to zero and so the amount of us tend to infinity. When this occurs the problem solution tends to an exact solution,

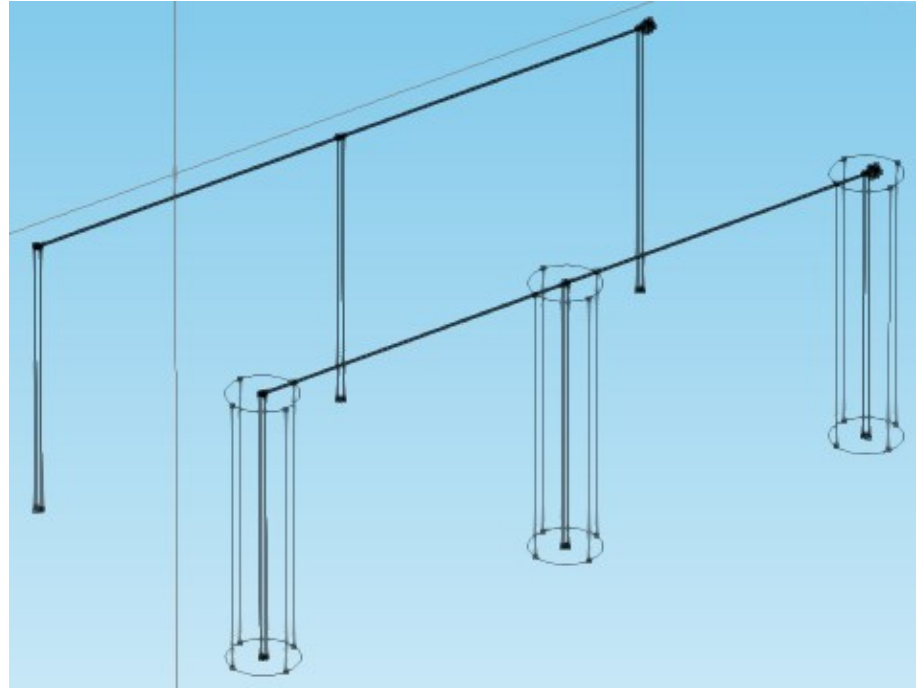

i.e., the smaller the size of the largest elements accuracy of the analysis results.

Modeling involves the reproduction of main geometric and electrical aspects of ground grid [15]. Figure 5 presents the soil modeling of details in detail. It illustrated three interconnected rods without concrete and three interconnected concreted rods. Soil characteristics, resistivity and depth are calculated and used in simulator in stratified three-tier model and forty meter radius.

Mesh construction detail is shown in Figure 5. Rods are made of copper with 5/8 inch in diameter and 2.4 meters long, on right its shown rods combined with concrete, being enclosure is $30 \mathrm{~cm}$ radius and 2.40 meters long. Distance between rods is 4,5 meters, distance between ground mesh is 3 meters. Simulations were done by inserting $200 \mathrm{~V}$ and $2000 \mathrm{~V}$ in each grounding system.

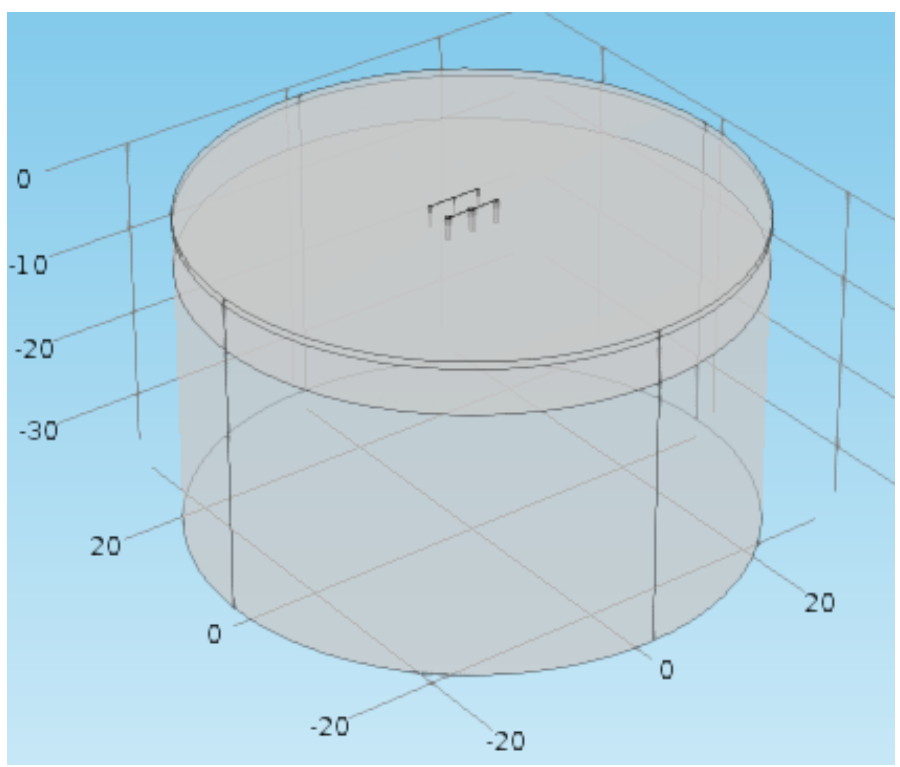

Fig. 6. Building of the soil in FEM simulation software on the grid and their properties.

Considering the distance on fall-off-potential $40 \mathrm{~m}$ between grounding system and current road was used this size to build the model like Figure 6.

\section{RESULTS}

\section{A. Data Acquisition}

The Table 1 shows characteristics of soil collected in the field during the rainy season and dry season. These data allow the comparison between soil resistance and response by the absorption and retention of water [16]. Second column corresponds to soil characteristics in dry season and third column corresponds to rainy season.

Figure 7 shows the resistance curves depending on the positioning of electrodes for same periods of year. The red line represents values obtained using three points in mesh without concrete and blue curve is the response of ground with concrete.

Fig. 5. Construction in FEM software of ground grid. 
TABLE I

DATA COLLECTION BEFORE THE RAINY SEASON.

\begin{tabular}{lcl}
\hline \hline Feature & Drought & Rainy \\
\hline \hline Soil Moisture & $25.0 \%$ & $70.0 \%$ \\
Soil Temperature & $32.2{ }^{\circ} \mathrm{C}$ & $26.3{ }^{\circ} \mathrm{C}$ \\
Humidity & $27.0 \%$ & $59.0 \%$ \\
Ambient Temperature & $31.0{ }^{\circ} \mathrm{C}$ & $28.4{ }^{\circ} \mathrm{C}$ \\
Resistance Grounding Concrete & $275.7 \Omega$ & $165.3 \Omega$ \\
Grounding Resistance Standard & $537.0 \Omega$ & $361.7 \Omega$ \\
Precipitation & $0,0 \mathrm{~mm}$ & $45.0 \mathrm{~mm}$ \\
\hline \hline
\end{tabular}

Figure 8 shows the ground due to the spacing of the rods resistance curve showing the increase of efficiency of the mesh after the concrete insertion along the rods. How much moisture in the soil after rain considerably alters response of soil resistivity, improving ground resistance. Blue line is no concrete ground resistance before the rain, and red line is the grounding strength concrete after rain.

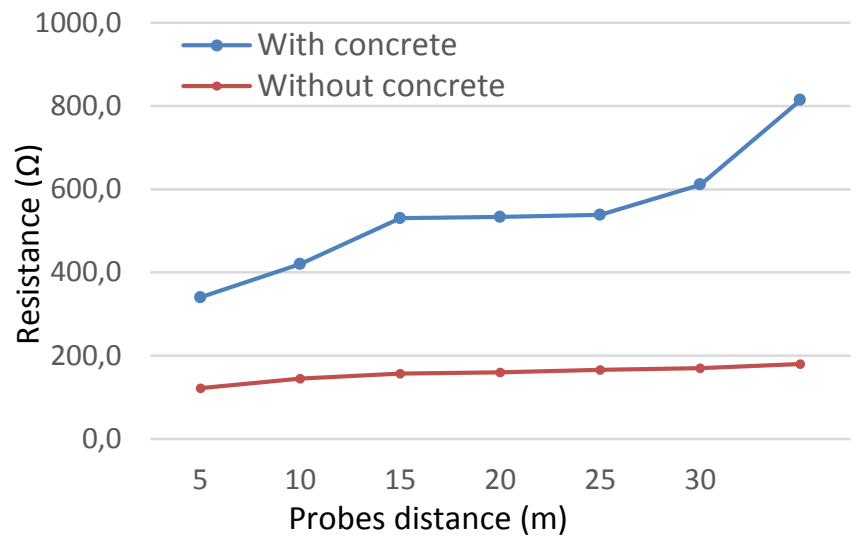

Fig. 7. Chart show grounding resistance at end of dry season in relation to distance from stems using Werner method.

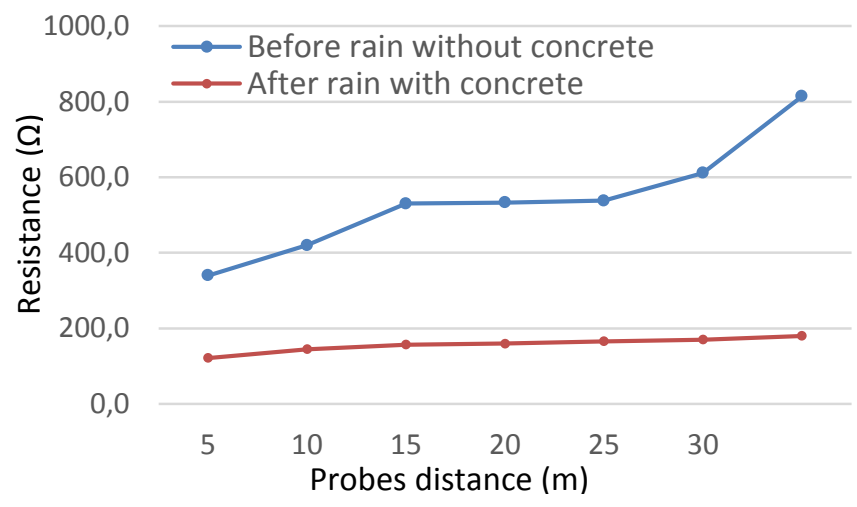

Fig. 8. Comparing ground not concretes rain and concreted after rain.

Wenner method used to measure soil resistivity, this method related to the amount of soil resistivity and the resistance measured. Wenner's method used in the 4 rods equally spaced ground straight. Two side rods used for the insertion of electrical current in the ground, since central rods used to determine tension. Wenner method considers the homogeneous ground and if it departs from rods is considered value of resistivity of same depth as distance between the rods [12]. The Table 2 shows acquired values were sampled only 4 values starting with 1 meter to 6 meters, because the space was short and the distance of 6 meters between rods already requires an area of length of 18 meters, and the length available for measurement was 20 meters.

TABLE II

WENNER METHOD

\begin{tabular}{ccc}
\hline \hline Distance & Drought & Rainy \\
\hline \hline $1 \mathrm{~m}$ & $125.0 \Omega$ & $815.3 \Omega$ \\
$2 \mathrm{~m}$ & $160.0 \Omega$ & $2030.2 \Omega$ \\
$4 \mathrm{~m}$ & $110.0 \Omega$ & $2771.4 \Omega$ \\
$6 \mathrm{~m}$ & $160.0 \Omega$ & $2113.5 \Omega$ \\
\hline \hline
\end{tabular}

Table 3 shows resistivity of soil layers over a longer period presenting lower humidity 3/10/2013 and higher humidity $04 / 20 / 2014$, according to values shown in Table 3 . Was built Figure 9 with depths of layers having the thicknesses changing according to the moisture retained by the soil.

\begin{tabular}{ccccc}
\multicolumn{5}{c}{ TABLE III } \\
SoIL RESISTIVITY \\
\hline \hline Layer & $10 / 03 / 2013$ & $10 / 17 / 2013$ & $12 / 04 / 2013$ & $04 / 20 / 2014$ \\
\hline \hline 1 & $352.93 \Omega$ & $1033.88 \Omega$ & $749.92 \Omega$ & $469.44 \Omega$ \\
2 & $1411.61 \Omega$ & $10062.9 \Omega$ & $3591.83 \Omega$ & $1663.14 \Omega$ \\
3 & $2795.98 \Omega$ & $623.3 \Omega$ & $404.78 \Omega$ & $1071.28 \Omega$ \\
\hline \hline
\end{tabular}

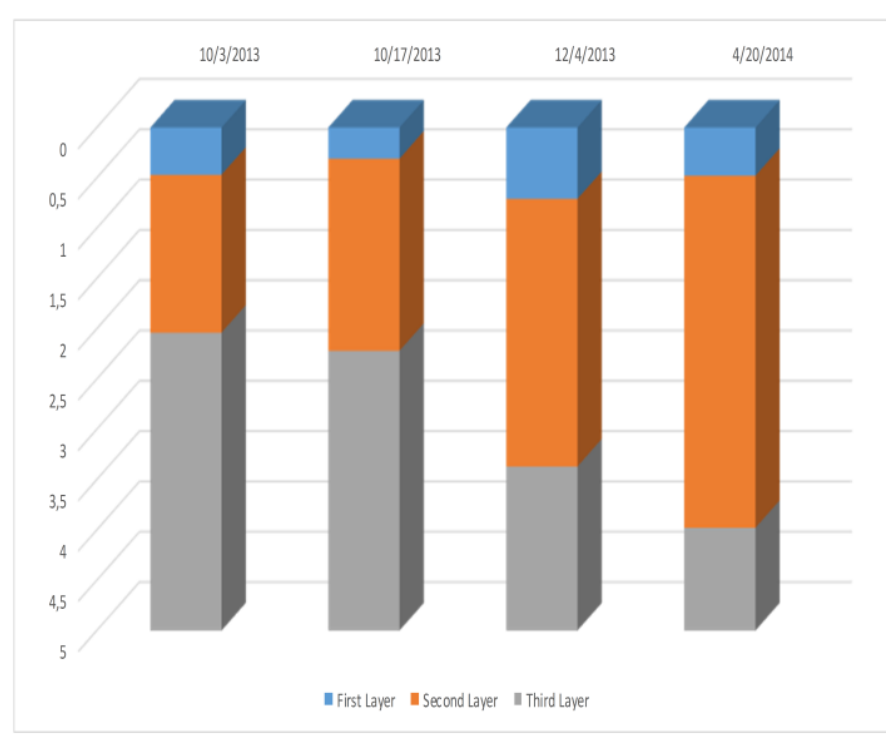

Fig. 9. Chart the depths of soil layers

The six grounding probes was tested in different soil moisture, on Figure 10 has shown de worst and better grounding resistance curve. The first probe made by concrete, gravel and salt, has the betters results on dry season and wet season.

Table IV shows de difference of grounding resistance between dry and raining season measured in Ohms. The first ground shows that concrete is better than any another grounding on wet season or dry season. The biggest difference 
TABLE IV

GROUNDING RESISTANCE

\begin{tabular}{lllllll}
\hline \hline & Gnd 1 & Gnd 2 & Gnd 3 & Gnd4 & Gnd 5 & Gnd 6 \\
\hline \hline Dry & 524 & 798 & 730 & 643 & 708 & 1769 \\
Wet & 213 & 367 & 477 & 451 & 603 & 1111 \\
\hline \hline
\end{tabular}

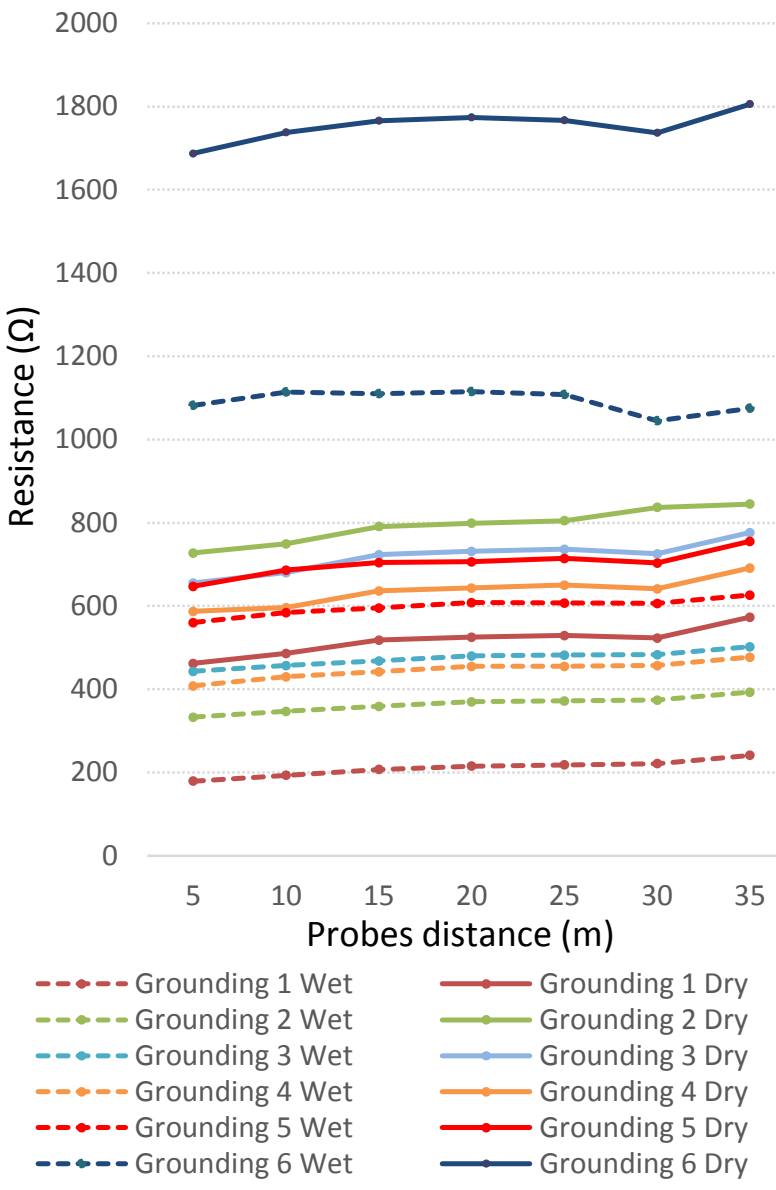

Fig. 10. Grounding Resistance Curves

on dry season was $337 \%$ and on dry season $521 \%$.

\section{B. Computational Method}

Figure 11 shows the equipotential lines form insert $200 \mathrm{~V}$

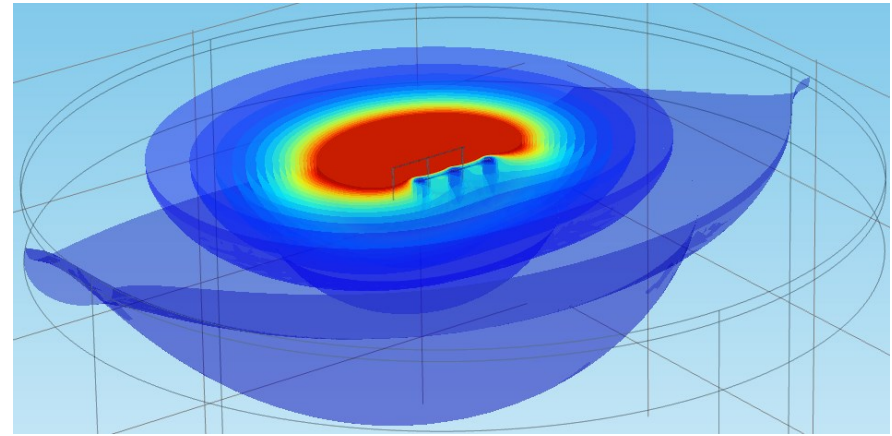

Fig. 11. Shows equipotential surfaces in soil and interaction between two grounds studied with inclusion of $200 \mathrm{~V}$. on rods of ground grid. Interaction with rods concreted ground grid. The outer loop ensures that there is a higher voltage drop, maximizing the absorption of electrical current through the ground grid.

Simulation of charge distribution in ground by inserting a

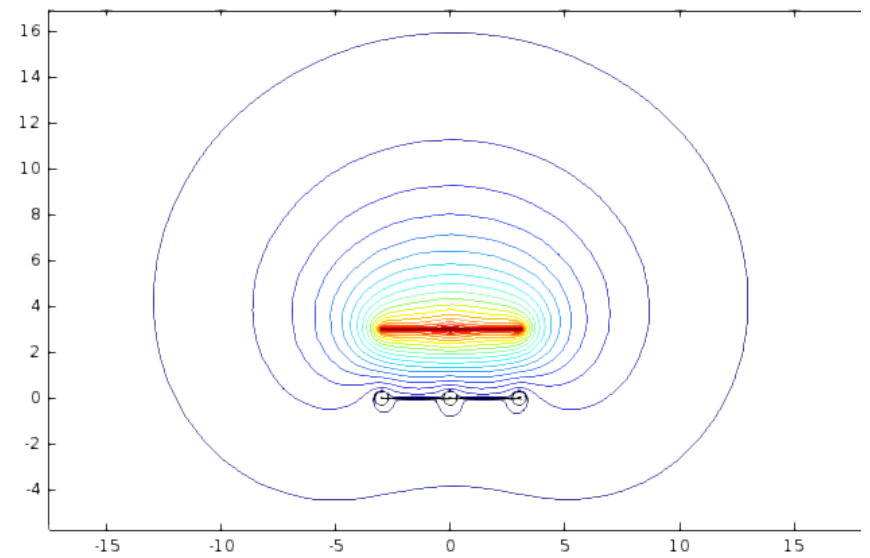

Fig. 12. Simulation of equipotential lines in plane parallel to surface of soil.

2000 V voltage can see in Figure 12.

\section{CONCLUSIONS}

As first measurements and studies in experimental ground on the dates of September 7 and October 3, 2013 has considerable difference in resistance of grounds with and without concrete after a long period of drought and after rain During dry season grounding with the rods wrapped in concrete already had a degree of improved efficiency that grounding without concrete. The concreted loop resistance was $275.7 \Omega$ and without concrete showed resistance $537.0 \Omega$ a difference of almost $200 \%$. Difference is accentuated by concrete characteristics such as moisture, its resistivity is smaller than ground contact area with ground is increased, which helps the current distribution in soil.

A study can be done is influence of meshes creating interaction between them, when there injection voltage in a mesh, there is the scattering voltage at this soil. Due to the proximity of ground grid, note change in the lines of equipotential caused the second ground grid. Figure 5 illustrates the difference in grounding resistance level in mesh without concrete before the rain and the mesh concreted after rain. Use of FEM to determine equipotential surfaces due to scattering of current through soil and its mesh with next ground with these images it is possible to study and see what electrical interaction between layers and substances buried in ground make to ground. Differences in responses are already expected between two meshes, we can put data in a computer simulator for verification of equipotential surfaces and consequently ground to ground response.

Several aspects to be analyzed, since strength of concrete in ground, moisture retention of concrete in relation to retention of moisture from soil. 


\section{REFERENCES}

[1] O. Vicente, "Study on the electrical behavior of concrete used in structural grounding systems," 2010.

[2] A. Nadler and H. Frenkel, "Determination of soil solution electrical conductivity from bulk soil electrical conductivity measurements by the four-electrode method," Soil Science Society of America Journal, vol. 44, no. 6, pp. 1216-1221, 1980.

[3] P. W. Rowland, "Industrial system grounding for power, static, lightning and instrumentation, practical applications," in Textile, Fiber and Film Industry Technical Conference, 1995., IEEE 1995 Annual. IEEE, 1995,

pp. 1-6.

[4] L. Cong-Li and P. Minfang, "A new approach for monitoring grounding grid of electrical power system," in Electronic Measurement and Instruments, 2007. ICEMI'07. 8th International Conference on. IEEE,

2007, pp. 4-419.

[5] W. P. Calixto, "Mathematical and computational methods applied to geoelectric prospecting with threedimensional stratification," In portuguese Ph.D. dissertation, 2012.

[6] J. B. J. Pereira, "Modeling of uncertainties in electrical grounding systems" In portuguese 2008.

[7] W. P. Calixto, L. M. Neto, M. Wu, H. J. Kliemann, S. S. de Castro, and K. Yamanaka, "Calculation of soil electrical conductivity using a genetic algorithm," Computers and Electronics in Agriculture, vol. 71, no. 1, pp. 1-6, 2010.

[8] E. J. Fagan and R. H. Lee, "The use of concreteenclosed reinforcing rods as grounding electrodes," Industry and General Applications, IEEE Transactions on, no. 4, pp. 337-348, 1970.

[9] J. Preminger, "Evaluation of concrete-encased electrodes," Industry Applications, IEEE Transactions on, no. 6, pp. 664-668, 1975.

[10] T. R. Brinner, J. D. Atkins, and M. O. Durham, "Electric submersible pump grounding," Industry Applications, IEEE Transactions on, vol. 40, no. 5, pp. 14181426, 2004.

[11] M. Santos, W. Cunha, and A. Nascimento, "Infrastructure in systems of Communication Technology", vol. 1, no. 1, 2010.

[12] G. Kindermann and J. M. Campagnolo, "Grounding Systems” In portuguese. Sagra- DC Luzzatto, 1992.

[13] J. Paknahad, K. Sheshyekani, F. Rachidi, and M. Paolone, "Lightning electromagnetic fields and their induced currents on buried cables. Part ii: The effect of a horizontally stratified ground," IEEE Transactions on Electromagnetic Compatibility, vol. 56, no. 5, pp. 1146-1154, Oct 2014.

[14] Y. Wang, R. Chen, S. Lin, J. Tian, J. Li, and M. Chen, "Calculation and analysis of the current carrying capability of electric cable based on finite element method," in Electrical Insulation and Dielectric Phenomena, 2009. CEIDP '09. IEEE Conference on, Oct 2009, pp. 307-310.

[15] J. A. Guemes and F. E. Hernando, "Method for calculating the ground resistance of grounding grids using fem," IEEE Transactions on Power Delivery, vol. 19, no. 2, pp. 595-600, April 2004.
[16] A. Habjanic and M. Trlep, "The simulation of the soil ionization phenomenon around the grounding system by the finite element method," IEEE Transactions on Magnetics, vol. 42, no. 4, pp. 867-870, April

[17] MA, Jinxi; DAWALIBI, Farid P. Extended analysis of ground impedance measurement using the fall-of-potential method. IEEE Transactions on Power Delivery, v. 17, n. 4, p. 881-885, 2002.

[18] MA, Jinxi; DAWALIBI, Farid P. Influence of inductive coupling between leads on ground impedance measurements using the fall-of-potential method. IEEE Transactions on Power Delivery, v. 16, n. 4, p. 739-743, 2001. 